\title{
Norois
}

Environnement, aménagement, société

$224 \mid 2012$

Agriculture paysanne, circuits courts, territoires périurbains

\section{Atlas permanent de la mer et du Littoral, fascicule $\mathrm{n}^{\circ} 6$}

Jean Renard

\section{(2) OpenEdition}

Journals

Édition électronique

URL : http://journals.openedition.org/norois/4305

DOI : $10.4000 /$ norois. 4305

ISBN : 978-2-7535-2157-5

ISSN : $1760-8546$

Éditeur

Presses universitaires de Rennes

Édition imprimée

Date de publication : 30 septembre 2012

Pagination : 91-92

ISBN : 978-2-7535-2155-1

ISSN : 0029-182X

Référence électronique

Jean Renard, «Atlas permanent de la mer et du Littoral, fascicule n6 ", Norois [En ligne], 224 | 2012, mis en ligne le 30 septembre 2012, consulté le 19 avril 2019. URL : http://journals.openedition.org/ norois/4305 

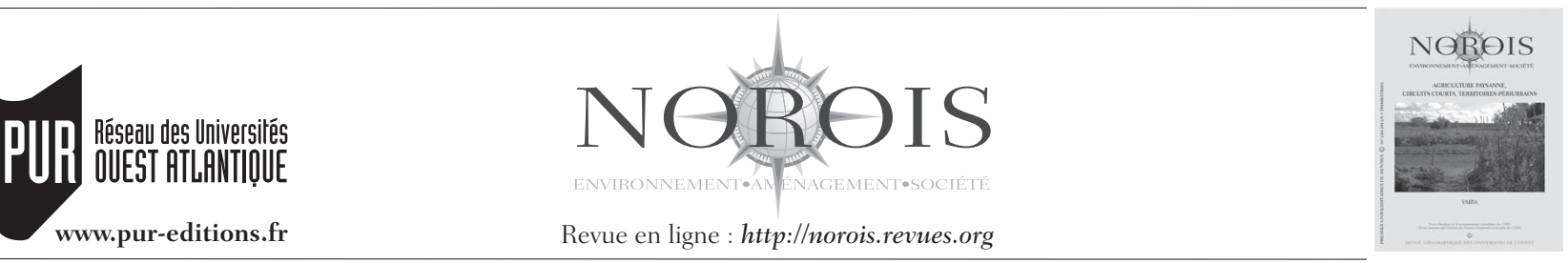

\section{COMPTE RENDU BIBLIOGRAPHIQUE}

\section{LETG - NAnTEs-GÉolitTomer, 2010. - Atlas permanent de la mer et du littoral, fascicule $\mathrm{n}^{\circ}$ 6, $48 \mathrm{p}$.}

L'équipe nantaise de géographes de la mer appartenant au laboratoire LETG associé au CNRS publie, après dix années de silence, le sixième fascicule de son Atlas permanent de la mer et du littoral. On ne peut que s'en réjouir. D'autant que cette édition est consacrée à un espace maritime original qu'est le golfe de Gascogne (El golfo de Vizcaya) partagé entre deux nations et lieu de multiples activités mais aussi de conflits et de partages territoriaux disputés. Si pour les hommes de la terre il s'agit d'un espace mal identifié, pour les marins c'est un lieu de forte identité et reconnu comme tel.

L'atlas décrit successivement, avec de magnifiques cartes en couleur et des commentaires bien informés, les particularités physiques et les ressources vivantes de cet espace maritime et des rivages, les populations qui occupent les littoraux, les activités présentes, tant les ports de commerce que les flottes de pêche ou les aspects touristiques (plaisance, patrimoine). Chemin faisant on comprend la diversité des façades des deux pays ainsi que les points communs. Les cartes et les commentaires qui les accompagnent sont traités à différentes échelles. Des études de cas (golfe du Morbihan, tempête Xynthia) alternant avec de cartes générales (effectifs des flottes de pêche par port, trafics des ports de commerce).

Certains documents comme la carte de la protection du patrimoine naturel dans le golfe du Morbihan (p. 14) ou celle des partitions territoriales du golfe sont difficiles à lire, mais elles expriment

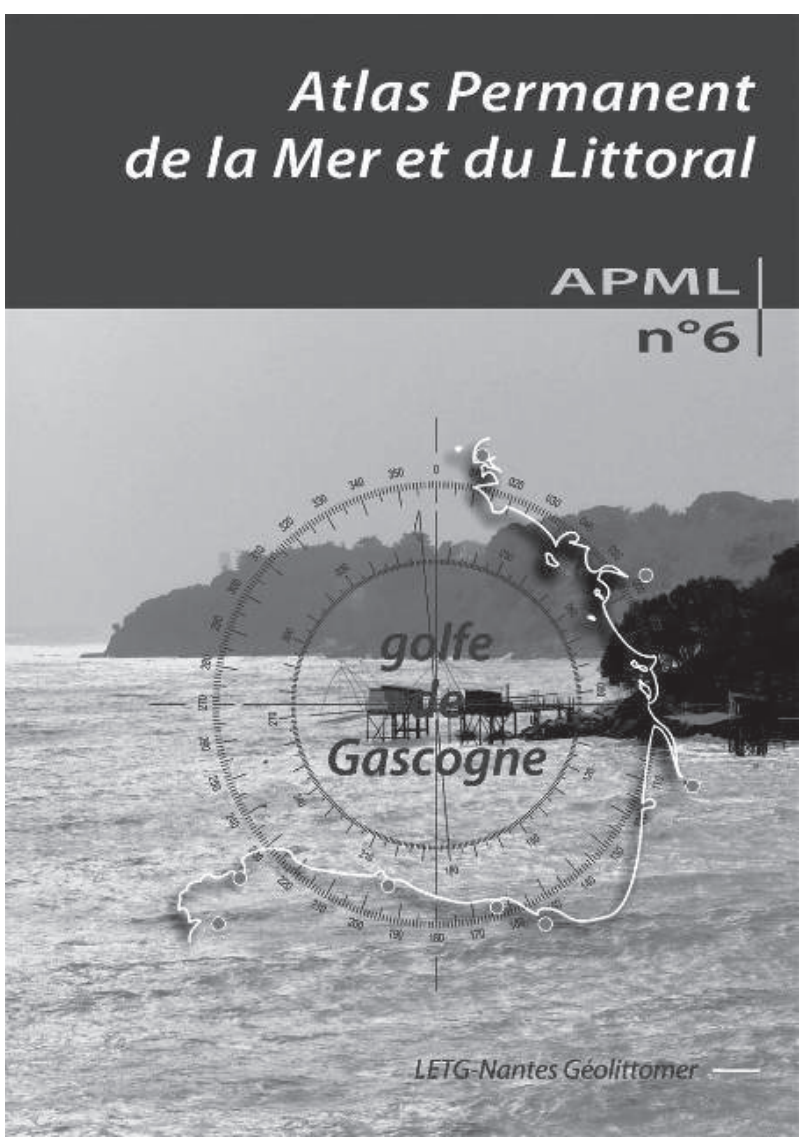

la complexité des choses et la réalité des conflits d'usage.

In fine on comprend mieux ce qui fait l'originalité de cet espace et ses problèmes et conflits, 
notamment avec les cartes des effectifs de bateaux de pêche entre les côtes espagnoles et la façade atlantique de la France. On se doit de souligner la diversité, la complémentarité des approches et les ouvertures sur des aspects jusqu'ici peu représentés, allant de la géohistoire aux énergies marine, même si rien n'est dit des projets d'éolien offshore.
Une brève bibliographie accompagne les cartes et les commentaires.

On ne peut que souhaiter une extension des analyses et observations au Royaume-Uni et au Portugal afin d'avoir une vision complète de l'ensemble des littoraux de l'Arc atlantique.

Jean RENARD 